\title{
COVID-19 ve okul öncesi yaş grubu ruh sağlığı
}

\section{COVID-19 and mental health of preschool children}

\begin{tabular}{|c|c|c|c|}
\hline Sirsen Şentürk Pilan & Burcu Özbaran & Gamze Yüksel & Elif Tortop \\
\hline eyhan Çalışan & Begüm Yuluğ & Sibel Helin Tokmak & רוlır \\
\hline ezen Köse & Serpil Erermiş & Zeki Yüncü D & \\
\hline
\end{tabular}

Ege Üniversitesi Tıp Fakültesi Hastanesi Çocuk ve Ergen Ruh Sağlığı ve Hastalıkları Anabilim Dalı, İzmir, Türkiye

\section{Öz}

Amaç: Bu çalışmada okul öncesi yaş grubunda olup psikiyatrik takibi devam eden çocukların COVID19 pandemisi ile ilgili uyum süreci ve psikiyatrik belirtilerindeki değişikliklerin Teletıp sistemi ile değerlendirilmesi amaçlanmıştır.

Gereç ve Yöntem: Bu çalışmaya psikiyatrik takibi devam eden okul öncesi yaş grubundaki hastalar alınmıştır. Randevu günlerinde Teletıp sistemi aracılığıyla görüşülerek covıd-19 pandemisi ile ilgili uyum sürecini değerlendirmek amacıyla araştırmacılar tarafından hazırlanan anket soruları sorulmuş ve kaydedilmiştir. Pandemi ve pandemi öncesi dönemdeki hastalık şiddetlerini değerlendirmek için Klinik Global İzlenim-Hastalık Şiddeti (KGi-Şiddet) ölçeği kullanılmıştır

Bulgular: Çalışmamıza dahil edilen 51 hastanın \%27,5'i kız, \%72,5'i erkektir. Yaş ortalaması $4,42 \pm 1,15$ 'tir. Psikiyatrik tanılarda birinci sırada Otizm Spektrum Bozukluğu $(\% 52,9)$, ikinci sırada Dikkat Eksikliği / Hiperaktivite Bozukluğu $(\% 21,6)$, üçüncü sırada ise Hafif Düzeyde Mental Retardasyon $(\% 13,7)$ yer almaktadır. Pandemi döneminde gözlenen birincil değişiklik olarak olguların $\% 25,5$ 'i sinirlilikte artış, \%19,6'sı kaygıda artış bildirmiştir. Hastaların uyku ve beslenme rutinleri sorgulandığında \%54,9'u uyku, \%39,2'si beslenme ile ilgili değiş̧iklik bildirmiştir. Hastaların pandemi öncesindeki KGi-Şiddet puanı $3,37 \pm 0,87$, pandemi dönemindeki ise $3,74 \pm 0,89$ olarak değerlendirilmiştir.

Sonuç: Okul öncesi yaş grubunda en sık saptanan yakınmalar sinirlilik, kaygı artışı ile uyku ve beslenme düzeni değişiklikleri olmuştur. Çalışmamız pandemi sürecinden etkilenme düzeylerini tespit etmek açısından yol gösterici olmuş ve çocuklara yaş gruplarına uygun bilgilendirmeler yapılmasının, Teletıp yolu ile tedavi ve takiplerinin devam etmesinin gerekliliği vurgulamıştır.

Anahtar Sözcükler: Pandemi, Covid-19, çocuk ve ergen ruh sağlığı, okul öncesi çocuk, 0-6 yaş, teletıp.

\section{ABSTRACT}

Aim: In this study, it was aimed to evaluate the changes in the adaptation process and psychiatric symptoms system of children in the preschool age group who are under psychiatric follow-up, related to the COVID-19 pandemic with the Telemedicine system.

Materials and Methods: Preschool children who are under psychiatric follow-up were included in this study. On the appointment days, the questionnaire prepared by the researchers in order to evaluate the adaptation process to the pandemic were asked and recorded through the Telemedicine system. Clinical Global Impression-Severity of IIIness (CGI-Severity) scale was used to evaluate the severity of illness for the pandemic and pre-pandemic period.

\footnotetext{
Sorumlu yazar: Birsen Şentürk Pilan

Ege Üniversitesi Tıp Fakültesi Hastanesi Çocuk ve Ergen Ruh

Sağlığı ve Hastalıkları Anabilim Dalı, İzmir, Türkiye

E-posta: drbirsensenturk@yahoo.com

Başvuru tarihi: 24.12.2020 Kabul tarihi: 09.03.2021
} 
Results: In our study, $27.5 \%$ of 51 patients were girls and $72.5 \%$ were boys. The average age is 4.42 1 1.15. Most frequently observed psychiatric diagnoses are Autism Spectrum Disorder (52.9\%), Attention Deficit and Hyperactivity Disorder (21.6\%), and Mild Intellectual Disability (13.7\%). As the primary change observed during the pandemic period, $25.5 \%$ of the cases reported increased irritability and $19.6 \%$ increased anxiety, 54.9\% change in sleep pattern and $39.2 \%$ change in nutritional routine. CGI-Severity score before the pandemic was evaluated as $3.37 \pm 0.87$, and as 3.74 \pm 0.89 during the pandemic period.

Conclusion: The most common complaints in the preschool age group were irritability, anxiety and sleep/ nutritional changes. Our study has been a guide in determining the levels of being affected by the pandemic period and emphasized the necessity of providing children an appropriate information for their age and continuing their treatment and follow-up through telemedicine.

Keywords: Pandemic, Covid-19, child and adolescent mental health, preschool child, 0-6 years, telemedicine.

\section{GiRiş}

Illk olarak Aralık 2019'da Çin'in Wuhan kentinde gözlenen COVID-19, hızlı bir yayılım göstermiş (1) ve 11 Mart'ta Dünya Sağlık Örgütü (WHO) tarafından pandemi olarak ilan edilmiştir (2).

Pandemi her yaş grubu için çok çeşitli zorlukları beraberinde getirmiştir. Bulaş korkusunun yanı sıra ebeveynlerin iş kayıpları, maddi kayıplar yaşadığı, çocuklar ve gençlerin sosyal destekten uzak yeni eğitim sistemine adapte olmaya çalıştığı, hemen herkesin bu belirsizlikle başa çıkmanın yollarını aradığı zorlu bir süreç olmaktadır. Okul öncesi çocuklar COVID-19 salgınını ve bu salgında neden bireysel ve toplumsal korunma önlemlerinin alınması gerektiğini anlamakta güçlük çekebilmekte ve bu anlamlandıramamanın sonucu olarak korkularını ve kaygılarını artıracak düşünceler üretebilmektedirler (3).

Pandemi döneminde sağlık sektöründe alınan önlemler kapsamında bulaş riskini azaltmak amacıla 23.03.2020 tarihinden itibaren Üniversite Hastanesi Çocuk ve Ergen Ruh Sağlığı ve Hastalıkları Anabilim Dalı'nda Teletıp uygulaması kullanılarak psikiyatrik görüşmeler yapılmış ve tedavileri düzenlenmiştir. 23.03.2020 tarihinde okulların kapatılması ve 04.04.2020 tarihinde ise 20 yaş altına sokağa çıkma yasağının getirilmesiyle okul öncesi yaş grubunun da hareket alanı azalmış olup park, kreş, anaokulu gibi sosyal etkileşim alanlarından uzak kalmışlardır (4). Teletıp aracılığıyla yapılan görüşmeler sırasında bu yaş grubunun psikiyatrik yakınmalarında değişim dikkati çekmiştir.

Tarihte, okul öncesi çocukların emosyonel ve davranışsal problemleri sıkça inmal edilmiş ve çocukların yeni oluşmaya başlayan özerkliklerinin geçici bir görünümü olarak düşünülmüştür (5). Ancak uzun dönemli çalışmalar emosyonel ve davranışsal problemlerinin yanı sıra özellikle içselleştirme ve dışsallaştırma problemleri olan okul öncesi çocukların; ilerleyen çocukluk ve ergenlik dönemlerinde ruh sağlığı problemleri açısından daha fazla risk altında olduklarını göstermiştir (6). Bilimsel kanıtlar beyin gelişiminin zorlu çocukluk çağı deneyimleri ve yoksulluğun yıkıcı etkilerine (7) ve maternal desteğin yapıcı etkilerine duyarlı olduğunu göstermektedir (8).

Küçük çocuklar ebeveynlerinin stresini hissetmekte ve endişelerini davranım problemi, karşı gelme ve öfke nöbetleri şeklinde gösterebilmektedirler. Ebeveynler okul öncesi çocuklarının daha huzursuz ve agresif olduklarını, oyuna dahil olma ve odaklanmada problemler yaşadığını fark edebilmektedirler. Bazı çocuklar biberon isteme, parmak emme, kendi kendine giyinme ve yemeyi reddetme, daha bağımlı ve talep edici olma, kucakta taşınmak isteme ve uyku problemi yaşama gibi tipik gerileme davranışları göstermeye başlayabilmektedirler. Çocuklarda yaşanan bu stres tepkileri, ebeveynlerin kendinden şüphe duymasına ve yetersiz hissetmesine, anlama ve empati kurmada güçlük yaşamasına, üzüntü hissinin artmasına, depresyona, kontrolsüzlüğe, uykusuzluğa, ebeveynlerin geri çekilmesi ve içe kapanmasına neden olabileceği gibi ebeveyn travmasını da tetikleyebilmektedir (9).

Normal motor-mental gelişim süreci geçiren çocuklar için bile birçok risk barındıran bu süreçte ek psikopatolojiye sahip çocuklar daha ayrıntılı değerlendirme ve ek müdahalelere gereksinim duyabilmektedir. Okul öncesi yaş grubunda en sık görülen tanılar uyaran eksikliği, uyum bozukluğu, otizm spektrum bozuklukları, genel 
gelişim geriliği, dikkat eksikliği-hiperaktivite bozukluğu olarak bildirilmiştir (10).

Literatürde pandemi döneminde 0-6 yaş grubunun sorunlarına dikkat çeken çalışma sayısı azdır. Çalışmamızda bu yaş grubunun pandemiye uyum süreci ve psikiyatrik belirtilerindeki değişiklikler Teletıp aracılığıyla değerlendirilmiş olup bu süreçte ele alınması gereken konulara ve psikososyal destek ihtiyacına dikkat çekmesi amaçlanmıştır.

\section{GEREÇ ve YÖNTEM}

Bu çalışmaya Ege Üniversitesi Çocuk ve Ergen Ruh Sağlığı ve Hastalıkları Anabilim Dalı 0-6 Yaş Polikliniğinde takipli, Haziran 2020 - Ağustos 2020 tarihleri arasında Teletıp aracılığıyla psikiyatrik değerlendirmesi yapılan 630 hasta içinden çalışmaya katılmayı kabul eden 51 hasta dahil edilmiştir. 0-6 yaş polikliniğinde bu yaş aralığındaki hastaların psikiyatrik tedavisi düzenlenmekte ve takibi yapılmaktadır. COVID19 pandemisi döneminde bu hastalar randevularının olduğu gün ve saatlerde Teletıp sistemi aracıllı̆ıyla aranarak hem kendileriyle hem de ebeveynleriyle görüşme yapılmış ve bu görüşmelerde kullandıkları ilaçlar, günlük aktiviteleri, uyum süreci sorgulanmış ve hasta değerlendirilerek hem tedavisi düzenlenmiş hem de ebeveynlerine psikoeğitim verilmiştir. Teletıp yöntemi olarak hastalar ve ebeveynleri ile telefon aracılığı ile görüşülmüştür. Bu görüşmelerde çalışmaya katılmayı kabul eden olgu ve ailelerine COVID-19 pandemisi ile ilgili uyum sürecini değerlendirmek amacıyla araştırmacılar tarafından hazırlanan anket soruları sorulmuş ve cevapları olgu veri formuna kaydedilmiştir. Klinik Global İzlenim-Hastalık Şiddeti (KGí-Şiddet) ölçeği kullanılmış, puanları kaydedilirken, mevcut hasta dosyalarındaki eski klinik değerlendirmeler pandemi öncesi dönemi değerlendirmek için kullanılmıştır. Pandemi dönemi için ise Tele Tıp aracılığıyla yapılan psikiyatrik değerlendirme göz önüne alınmıştır.

Çalışmaya katılmayı kabul eden hasta ve yasal vasisine çalışma hakkında ayrıntılı bilgi verilerek tıbbi verilerinin yayınlanabileceğine ilişkin yazıı onam belgesi online olarak (WhatsApp Messenger ya da elektronik posta yolu ile) alınmıştır. T.C. Sağlık Bakanlığı Sağlık Hizmetleri Genel Müdürlüğü Bilimsel Araştırma Kurulu'ndan onay alınarak Ege Üniversitesi Tıp Fakültesi Hastanesi Tıbbi Araştırmalar Etik Kurulu'ndan da etik kurul onayı alınmıştır (Karar no: 20-6T/45 Tarih:10.06.2020).

\section{Değerlendirme Araçları}

Anket: Hastalara uygulanan anket çalışmacılar tarafından hazırlanmıştır. Ankette hastanın yaşı, tanısı, kullandığı ilaçları, özel eğitim alıp almadığı, aile yapısı, evde sağlık çalışanı olup olmadığı, çevresinde COVID-19 enfeksiyonu geçiren olup olmadığı, hastanın günlük aktiviteleri, uyku ve beslenme düzenindeki değişiklikler, psikiyatrik durumundaki değişiklikler vb. durumlar sorgulanmıştır.

Klinik Global İzlenim Ölçeği-Hastalık Şiddeti (KGI-Şiddet): KGi-Şiddet, bir hastanın tedavi başlanmadan önce ve başlandıktan sonra klinisyenin hastanın işlevselliği hakkındaki izlenimini kaydetmesini sağlamak için yapılan bir ölçektir. Ölçeği kullanan klinisyen hastalıkla ilgili bilgi ve deneyimlerinin doğrultusunda, hastalığın şiddeti ile belirtilerdeki düzelmenin derecesini, 1 'den 7'ye uzanan likert tipi bir derecelendirme üzerinde değerlendirir. (1- normal, hasta değil, 2sınırda hasta, 3- hafif derecede hasta, 4- orta derecede hasta, 5- belirgin derecede hasta, 6- ileri derecede hasta, 7- en ileri derecede hasta) (11).

The Diagnostic and Statistical Manual of Mental Disorders, Fifth Edition (DSM-5): Amerikan Psikiyatri Birliği (APA) tarafından yayınlanan taksonomi ve tanı aracı olan Ruhsal Bozuklukların Tanısal ve İstatistiksel El Kitabı'nın 2013 güncellemesidir (12).

\section{İstatistiksel Analiz}

$\mathrm{Bu}$ çalışmadaki verilerin istatiksel analizi SPSS 25 paket programı ile yapılmıştır. Hastaların sosyodemografik verileri, psikiyatrik tanıları, tedavileri anket soruları tanımlayıcı istatistiksel analiz yöntemleri-frekans analizleri ile değerlendirilmiştir. Veriler sayı ve yüzde şeklinde sunulmuştur. Tüm analizler için $p$ değerinin 0.05 'in altında olması istatistiksel olarak anlamlı kabul edilmiştir.

\section{BULGULAR}

Çalışmaya dahil edilen 51 hastanın \%27,5'i (n:14) kız, \%72,5'i (n:37) erkektir. Katılımcıların ortalama yaşı $4,42 \pm 1,15$ 'tir. Çalışmaya dahil edilen hastaların \%86,3'ü (n:44) çekirdek aile ile, $\% 7,8$ 'i (n:4) çekirdek aile ve aile büyükleri ile beraber, \%5,9'u (n:3) tek ebeveyn ile beraber yaşamaktadır. Hastaların yakın çevresinde COVID19 enfeksiyonu sebebiyle hasta olan/ölen/temasl olup izole edilen birey bulunmamaktadır. 
Tablo-1. Sosyodemografik veriler.

\begin{tabular}{lc}
\hline Cinsiyet & $\mathbf{n}(\%)$ \\
Kız & $14(\% 27,5)$ \\
Erkek & $37(\% 72,5)$ \\
\hline Yaş (yıl) & $4.42 \pm 1.15$ \\
Kız & $3.89 \pm 1.34$ \\
Erkek & $4.62 \pm 1.03$ \\
\hline Aile Özelliği & $\mathbf{n}(\%)$ \\
Çekirdek Aile & $44(\% 86,3)$ \\
Geniş Aile & $4(\% 7,8)$ \\
$\quad$ Tek ebeveyn & $3(\% 5,9)$ \\
\hline Evde Sağlık Çalışanı & $\mathbf{n}(\%)$ \\
Var & $4(\% 7,8)$ \\
$\quad$ Yok & $47(\% 92,2)$ \\
\hline Salgından Etkilenen Yakını & $\mathbf{n}(\%)$ \\
$\quad$ Var & 0 \\
Yok & $51(\% 100)$ \\
\hline
\end{tabular}

Tablo-2. Psikiyatrik tanı.

\begin{tabular}{lll}
\hline Psikiyatrik Tanı & $\mathbf{n}$ & $\%$ \\
\hline Otizm Spektrum Bozukluğu & 27 & 52,9 \\
Dikkat Eksikliği / Hiperaktivite Bozukluğu & 11 & 21,6 \\
Hafif Düzeyde Mental Retardasyon & 7 & 13,7 \\
Davranışsal ve Duygusal Diğer Bozukluklar & 5 & 9,8 \\
Kaygı (Anksiyete) Bozukluğu & 2 & 3,9 \\
Iletişim Bozukluğu & 2 & 3,9 \\
Orta Düzeyde Mental Retardasyon & 1 & 2 \\
\hline
\end{tabular}

*Bazı olgularda birden fazla psikiyatrik tanı bulunmaktadır. Sayı ve yüzdeler her tanı için ayrı ayrı hesaplanmıştır.

Bu çalışmaya dahil edilen hastaların \%7,8'i (n:4) evde sağlık çalışanı ile birlikte yaşamaktadır. Sosyodemografik veriler Tablo-1'de gösterilmiştir.

Çalışmaya katılan hastalardaki psikiyatrik tanılarda birinci sırada \%52,9 (n:27) ile Otizm Spektrum Bozukluğu yer almaktadır. İkinci sırada \%21,6 (n:11) ile Dikkat Eksikliği / Hiperaktivite Bozukluğu, üçüncü sırada ise \%13,7 (n:7) ile Hafif Düzeyde Mental Retardasyon yer almaktadır. Hastaların psikiyatrik tanıları Tablo2'de özetlenmiştir.

Çalışmaya katılan hastaların \%15,7'sinin (n:8) antipsikotik ilaç kullandığı, \%2'sinin (n:1) antihistaminik ilaç kullandığı, \%82,3'ünün (n:42) ise ilaç kullanmadığı tespit edilmiştir.
Hastaların pandemi sürecinde yaptığı etkinlikler ve nası vakit geçirdikleri sorgulanarak $\% 84,3$ 'ünün $\quad(\mathrm{n}: 43)$ televizyon izlediği, \%54,9'unun (n:28) internette vakit geçirdiği, \%33,3'ünün (n:17) hobileriyle ilgilendiği, \%17,6'sının (n:9) bilgisayar oyunu oynadığı, \%3,9'unun (n:2) anaokulundan verilen derslere çalıştığı, \%2'sinin (n:1) ise spor yaptığı öğrenilmiştir. Bu hastaların \%82,4'ünün (n:42) bu süreçte ailecek etkinlikler yaptığı bilgisi edinilmiştir. Hastalara imkân olsaydı yapmak istedikleri üç şey sorulmuştur. Verdikleri cevaplar değerlendirildiğinde \%68,6'sının (n:35) sokağa çıkmak istediği, \%13,7'sinin (n:7) okula gitmek istediği, \%5,9'unun (n:3) arkadaşlarıyla vakit geçirmek istediği öğrenilmiştir. \%2'si (n:1) farklı 
cevaplar vermiş ve \%9,8'i (n:5) herhangi bir istek belirtmemiştir. Hastaların \%31,4'ünün (n:16) salgınla ilgili haberleri izlediği ve bu hastaların \%5,9'unun (n:3) bu haberlerden çok etkilendiği öğrenilmiştir. Salgınla ilgili haberleri izleyen hastaların \%7,8'inin (n:4) bu haberlerden orta derecede, \%11,8'inin (n:6) hafif derecede etkilendiği \%5,9'unun (n:3) hiç etkilenmediği bilgisine ulaşılmıştır.

Pandemi döneminde gözlenen birincil değişiklik olarak olguların \%25,5'i (n:13) sinirlilikte artış, $\% 19,6$ 'sı (n:10) kaygıda artış olduğunu bildirmiştir. Bu değişiklikler Şekil-1'de belirtilmiştir.
Hastaların uyku ve beslenme değişikliklerine ayrıca bakıldığında \%54,9'u (n:28) uyku ile ilgili değişiklikler, \%39,2'si (n:20) beslenme ile ilgili değişiklikler olduğunu belirtmiştir. Pandemi döneminde gözlenen uyku-beslenme değişiklikleri ile ilgili bilgiler Şekil-2'de gösterilmiştir.

Hastaların pandemi öncesindeki KGi-Şiddet puanı $3,37 \pm 0,87$, pandemi dönemindeki KGiŞiddet puanı ise $3,74 \pm 0,89$ olarak değerlendirilmiştir. Aradaki fark istatistiksel olarak anlamlıdır $(p<0.05)$.

\section{Birincil Psikiyatrik Belirti n(\%)}

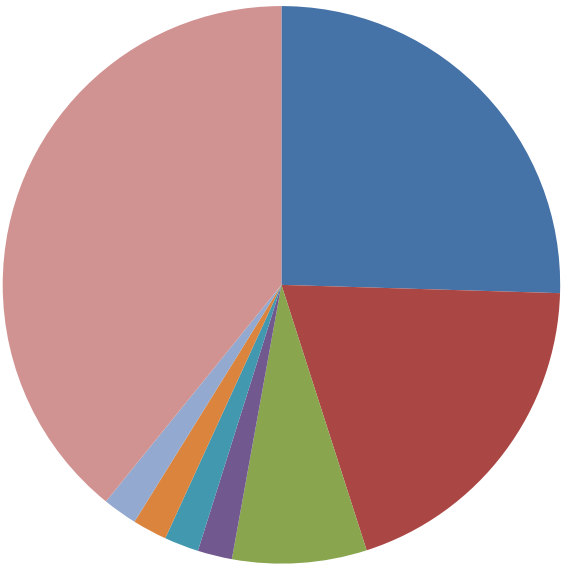

- Sinirlilikte Artış / n=13(\%25,5)

Kaygıda Artış $n=10(\% 19,6)$

- Hareketlilikte Artış / n=4(\%7,8)

- Uykuda Azalma / n=1(\%2)

— Iştahta Azalma / n=1(\%2)

- Işstahta Artma / n=1(\%2)

Diğer / n=1(\%2)

Değişiklik Yok / n=20(\%39,2)

Şekil-1. Pandemi dönemindeki psikiyatrik ve vejetatif belirtiler.

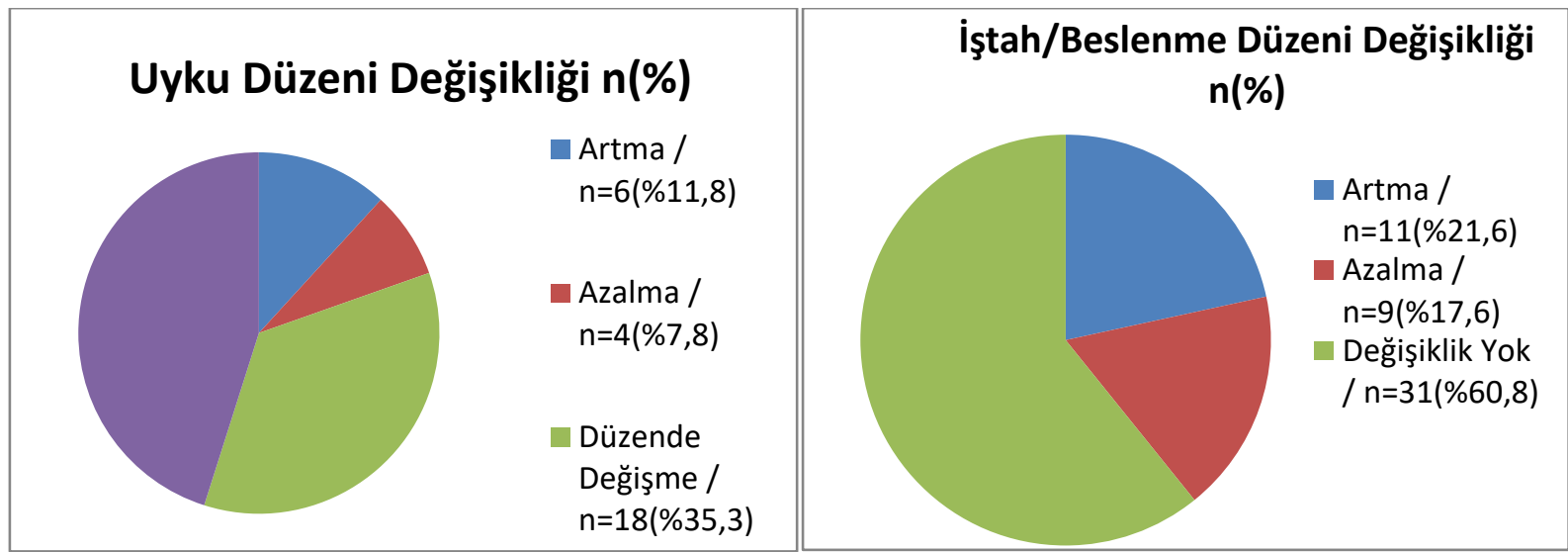

Şekil-2. Pandemi dönemindeki vejetatif belirtiler. 


\section{TARTIŞMA}

COVID-19 pandemisi 2020 Şubat ayından itibaren dünya çapında yaşamı derinden etkileyen bir salgın haline gelmiştir. Bu salgının sadece sağlık üzerinde değil aynı zamanda ekonomik, sosyal, toplumsal ve ruhsal alanlarda da etkilenmeye neden olmuştur. Salgın nedeniyle alınan önlemler kapsamında meydana gelen tecrit, temas kısıtlamaları ve ekonomik olarak etkilenme düzeyi, ülkelerdeki psikososyal ortama tam bir değişiklik getirmiştir. Bu önlemler, çocukların ve ergenlerin ruh sağlığını önemli ölçüde tehdit etme potansiyeline sahiptir (13).

Çocuklar, COVID-19 pandemisinin psikolojik etkisine kayıtsız kalamamışlardır. Sadece kendilerinin değil aynı zamanda ebeveynlerinin de stresinin yanı sıra korkular, belirsizlikler, rutinlerinde önemli değişiklikler yaşamışlardır (9). Alınan önlemler çerçevesinde karantina süreci hayat düzenini oldukça etkilemiş, düzen bozulması ve aktivitelerin azalması sonucu evde oluşan can sıkıntısı, sevdiklerinden ayrııma, hastalık durumuyla ilgili belirsizlik ve var olan özgürlük hissinin kaybedilmesinin kişilerde dramatik etki yaratabileceği gözler önüne serilmiştir (14). Bu durumun sağlıklı çocuklara ruhsal etkileri dışında psikiyatrik hastalığı sebebiyle çocuk psikiyatri kliniklerinde izlemde olan çocuklar için de olumsuz etkilerinin olması kaçınılmazdır (15).

Bizim çalışmamızda olguların ortalama yaşı $4,42 \pm 1,15$ 'tir. Olguların hiçbirinin yakın çevresinde COVID-19 enfeksiyonu sebebiyle hasta olan/ölen/temaslı olup izole edilen birey bulunmamaktadır. Bu durum okul öncesi yaş grubunda çocuğu olan ailelerin bulaşı önleme tedbirleri konusunda daha hassas olduğunu veya damgalanma korkusuyla bu bilgileri gizlemiş olabileceklerini düşündürmüştür. Yakın çevrede böyle bireyler olmasa da COVID-19 hayatın her alanında varlığını hissettirmektedir. Küçük çocuklar, tüm çocuklar gibi bu evrensel yaşam değişimini algılasalar da meydana gelen değişiklikleri anlamakta büyüklerine göre güçlük çekebilir ve bunu sinirlilik artışı olarak yansıtabilir (16).

Çocukların bir kısmı geçici bir stresin yönetiminde bazı kaygı belirtileri gösterse de uzun vadede ağır bir ruhsal problem yaşamazlar; ancak daha önceden psikiyatrik tanısı olan çocuklar veya travmaya maruz kalmış olanlar için bu risk daha da artmaktadır (17). Yapılan çalışmalarda okul çağı öncesi çocukların stres yönetiminde görülen sorunlar: anne ve babaya aşırı yapışma, konuşma sorunları, davranış ve becerilerde gerileme, iştahsızlık, uyku sorunları olarak tespit edilmiştir (17). Bizim çalışmamızda da yazınla uyumlu bulgular elde edilmiştir.

Çalışmamıza dahil edilen vakaların önemli bir kısmında tespit edilen Dikkat Eksikliği/Hiperaktivite Bozukluğu ve Hafif Düzeyde Mental Retardasyon gibi ek tanıların varlığı, çocuğun hastalığı anlamasını etkilemekte ve tedavi uyumunu bozabilmektedir (18).

Çalışmamızda olguların\%84,3'ünün $\quad(n=43)$ vaktini televizyon izleyerek geçirmesi dikkat çekmiştir. \%31,4'lük bir kesim ise salgınla ilgili haberleri izlediğini belirtmiştir. Okul öncesi çocukların sosyal iletişim becerilerinin ev dışında oyun oynamayla doğru orantılı, ekran maruziyeti ile ters orantılı olarak geliştiği (19) göz önüne alındığında pandemi dönemindeki sosyal hayatın kısıtlanıp televizyon maruziyetinin artmasının okul öncesi çocuklar için risk oluşturduğu görülmektedir. Çalıştığımız yaş grubundaki çocukların evdeki yönetimleri çok önemlidir. Değişimleri kavramada yaşadıkları güçlük onları ebeveynlerine daha yakın olmaya teşvik eder, kendilerinden büyük çocuklara göre daha fazla talepte bulunurlar, bu da ebeveynleri veya bakım verenlerini strese sokabilir. Bu nedenle, küçük çocukların yanında ebeveynlere de kendi stres yönetimlerini sağlayabilmek için destek olmak gerekir (16).

Literatür tarandığında pandemi sürecinde psikiyatrik takipteki okul öncesi yaş grubunda olan olgulara dair çok az çalışmaya rastlanmıştır. Çalışmamızın Teletıp yöntemini kullanarak okul öncesi yaş grubu psikiyatrik takipli olgulara müdahale ve tedaviye yönelik alanlarda literatüre katkı sağlayacağı düşünülmektedir. COVID-19 pandemisinin öngörülemez oluşu ve belirsizliği, alınan önlemler çerçevesinde fiziksel mesafelerin artması ve süreç sonucunda ortaya çıkan ekonomik çöküş ruh sağlığı sorunları riskini artırabilir ve sağlık eşitsizliklerini şiddetlendirebilir (20). Sağlık hizmetlerine erişim eksikliği de özellikle psikiyatrik takipli olguların tedavilerinde gecikmeye neden olarak sonuçları kötüleştirebilir (13). Çalışmamız bu sebeple büyüme çağındaki okul öncesi yaş grubundaki çocukların etkilenme düzeylerini ortaya çıkarmak, normal gelişim özelliklerinin yanı sıra ek psikiyatrik tanılarını ele almak, psikiyatrik takiplerindeki devamlılı̆ın önemini vurgulamak, çocukların ileriki dönem ruh 
sağlığı problemlerini ön görmek açısından önem taşımaktadır.

\section{SONUÇ}

COVID-19 pandemisi toplum üzerinde çok farklı psikososyal etkilenmeye neden olmuştur ve bunlardan çocukların çok fazla etkilendiği gözlemlenmiştir. Bulaşı önlemek amacıyla getirilen önlemler onların ruh sağlığını etkileyebilmektedir. Çalışmamı $0-6$ yaş grubunda psikiyatrik tanıları olup takipleri devam eden çocukların COVID-19 pandemi sürecinden etkilenme düzeylerini tespit etmek açısından yol gösterici olmuştur. Pandemi dönemde alınacak tedbirler hem çocuğun normal gelişim sürecinin devamlılığ hem de ruhsal iyilik halinin korunması açısından önem taşımaktadır. Pandemi sürecinde çocuklara yaş gruplarına uygun bilgilendirmeler yapılmasının ve bulaş riski olması sebebiyle yüz yüze görüşmelerin kısıtlandığı şartlarda Teletıp yolu ile tedavi ve takiplerinin devam etmesinin gerekliliği çalışmamızda vurgulanmıştır.

\section{Çıkar çatışması}

Çıkar çatışması bulunmamaktadır.

\section{Kaynaklar}

1. Wang Y, Wang Y, Chen Y, Qin Q. Unique epidemiological and clinical features of the emerging 2019 novel coronavirus pneumonia (COVID-19) implicate special control measures. J Med Virol. 2020; 92 (6): 568-76.

2. WHO Director-General's opening remarks at the media briefing on COVID-19 - 11 March 2020 [Internet]. [a.yer 22 Kasım 2020]. Erişim adresi: https://www.who.int/director-general/speeches/detail/who-directorgeneral-s-opening-remarks-at-the-media-briefing-on-covid-19---11-march-2020

3. Caykus E, Mutlu T. Ways to Promote Children' Resiliency to the COVID-19 Pandemic Suggestions For Families, Teachers and Mental Health Specialists / COVID-19 Pandemi Sürecinde Çocukların Psikolojik Dayanıklıı̆ını Güçlendirme Yolları: Ailelere, Öğretmenlere ve Ruh Sağlığı Uzmanlarına Öneriler. 31 Mayıs 2020; 7: 95-113.

4. Cluver L, Lachman JM, Sherr L, Wessels I, Krug E, Rakotomalala S, vd. Parenting in a time of COVID-19. Lancet Lond Engl. 11 2020; 395 (10231): e64. 5. Black MM, Jukes MCH, Willoughby MT. Behavioural and emotional problems in preschool children. The Lancet Psychiatry, 4 (2), 89-90. doi:10.1016/s22150366(17)30005-6

5. Black MM, Jukes $\mathrm{MCH}$, Willoughby MT. Behavioural and emotional problems in preschool children. Lancet Psychiatry. 2017; 4 (2): 89-90.

6. Bornstein MH, Hahn C-S, Suwalsky JTD. Developmental Pathways among Adaptive Functioning and Externalizing and Internalizing Behavioral Problems: Cascades from Childhood into Adolescence. Appl Dev Sci. 2013; 17 (2): 76-87.

7. Noble KG, Houston SM, Brito NH, Bartsch H, Kan E, Kuperman JM, vd. Family income, parental education and brain structure in children and adolescents. Nat Neurosci. Mayıs 2015; 18 (5): 773-8.

8. Luby JL, Belden A, Harms MP, Tillman R, Barch DM. Preschool is a sensitive period for the influence of maternal support on the trajectory of hippocampal development. Proc Natl Acad Sci U S A. 17 Mayıs 2016; $113(20):$ 5742-7.

9. Imran N, Zeshan M, Pervaiz Z. Mental health considerations for children \& adolescents in COVID-19 Pandemic. Pak J Med Sci. Mayıs 2020; 36 (COVID19-S4): S67-72.

10. Sevgen $\mathrm{FH}$, Altun $\mathrm{H}$. Presenting complaints and psychiatric diagnoses in childrenchildren aged 0-5 years presented to a child psychiatry and adolescent clinic -. Psychiatry Behav Sci. 2017; 7 (4): 205-11.

11. Guy W, Clinical Global Impressions. ECDEU Assesment Manual for Psychopharmacology Revised. 1976 Rockville, MD: US Department of Health, Education, and Welfare; Public Health Service, Alcohol; Drug Abuse, and Mental Health Administration; National Institute of Mental Health. pp. 218-22.

12. Amerikan Psikiyatri Birliği Ruhsal Bozuklukların Tanısal ve Sayımsal El Kitabı (DSM V). Beşinci Baskı. Ankara: Hekimler Yayın Birliği; 2014.

13. Fegert JM, Vitiello B, Plener PL, Clemens V. Challenges and burden of the Coronavirus 2019 (COVID-19) pandemic for child and adolescent mental health: a narrative review to highlight clinical and research needs in the acute phase and the long return to normality. Child Adolesc Psychiatry Ment Health [İnternet]. 12 Mayıs 2020 [a.yer 28 Haziran 2020]; 14. Available from: https://www.ncbi.nlm.nih.gov/pmc/articles/PMC7216870/ 
14. Brooks SK, Webster RK, Smith LE, Woodland L, Wessely S, Greenberg N, vd. The psychological impact of quarantine and how to reduce it: rapid review of the evidence. Lancet Lond Engl. 14 2020; 395 (10227): 912-20.

15. Sahbudak B, Emiroğlu N. COVID-19 Pandemic and Mood Disorders in Children and Adolescents. Turk J Child Adolesc Ment Health. 01 Temmuz 2020; 27: 59-63.

16. Mental health and psychological resilience during the COVID-19 pandemic [Internet]. [a.yer 16 Eylül 2020]. Available from: https://www.euro.who.int/en/health-topics/health-emergencies/coronavirus-covid19/news/news/2020/3/mental-health-and-psychological-resilience-during-the-covid-19-pandemic

17. 2420201236-cocuklarCOVID.pdf [internet]. [a.yer 22 Kasım 2020]. Erişim adresi: https://www.psikiyatri.org.tr/uploadFiles/2420201236-cocuklarCOVID.pdf

18. Froechlich-Santino W, Steiner H, Shaw RJ. Psychiatric Assesment of the Physically III Child [Internet]. Psychiatric Care of the Medical Patient. Oxford University Press; [a.yer 22 Kasım 2020]. Available from: www.oxfordmedicine.com/view/10.1093/med/9780199731855.001.0001/med-9780199731855-chapter-79

19. Hinkley T, Brown H, Carson V, Teychenne M. Cross sectional associations of screen time and outdoor play with social skills in preschool children. PloS One. 2018; 13 (4): e0193700.

20. Moreno C, Wykes T, Galderisi S, Nordentoft M, Crossley N, Jones N, vd. How mental health care should change as a consequence of the COVID-19 pandemic. Lancet Psychiatry. Eylül 2020; 7 (9): 813-24. 